\title{
¿Es posible un consenso social sobre el aborto?
}

\author{
ANIBAL FAÚNDES(1) y JOSÉ BARZELATTO(2)
}

Se estima que ocurren 46 millones de abortos cada año en el mundo; que el $26 \%$ de todos los embarazos, o sea uno de cada cuatro termina en aborto provocado, y que una de cada 28 mujeres de 15 a 45 años de edad se hace un aborto cada año en el mundo.

Más grave aún, desde el punto de vista de la salud, es que, aproximadamente, la mitad de los abortos en el mundo se realiza en forma "insegura", o sea, por alguien no calificado o en condiciones técnicas y de higiene inapropiadas. En general, el 80 a $90 \%$ de los abortos se realiza en condiciones de riesgo y son responsables de una alta proporción de las muertes relacionadas con el embarazo, y por un número mucho mayor de mujeres que sufre secuelas graves como esterilidad y dolor pélvico crónico. Sin mencionar el significativo porcentaje de recursos sanitarios, siempre escasos, que deben destinarse a la atención de estas mujeres.

Lo increíble es que se conocen cuáles intervenciones son eficientes para reducir los abortos, pero en lugar de prestar atención a implementar estas medidas, la mayor parte de las personas que discute el problema se limita a discutir si se está a favor o en contra del aborto. La verdad es que ese es un falso dilema. Nadie esta a favor del aborto, porque a ninguna mujer le gusta tener uno y nadie desea que otras personas tengan que abortar. La verdadera diferencia es que algunas personas creen que la solución del problema es declararlo ilegal y penalizar a la mujer que aborta, mientras que otros creemos que eso no resuelve nada, porque está demostrado que no es eficaz para reducir los abortos, además de ser injusto y acarrear graves consecuencias para las mujeres y para la sociedad.

De hecho, los países con las menores tasas de abortos en el mundo, son los de Europa Occidental, donde el aborto es legal y de fácil acceso, en cambio en América Latina, donde las leyes son muy restrictivas, las tasas son 5 a 8 veces más elevadas. Esos países con bajas tasas de aborto reúnen otras condiciones que favorecen que las mujeres que no desean tener un hijo raramente se embaracen: educación en sexualidad desde la infancia, mayor igualdad de poder entre mujeres y hombres, amplio conocimiento y acceso a todos los métodos anticoncepcionales. Además, ofrecen protección social y económica a toda mujer que desea tener un hijo.

En América Latina, incluyendo Chile, la educación en sexualidad continúa siendo un tabú, el acceso a métodos anticonceptivos no es fácil para las mujeres más pobres y para las adolescentes; y los hombres se consideran con derecho a disponer del cuerpo de la mujer, la que no puede controlar cuándo o en que condiciones tener sus relaciones sexuales. Todo eso lleva a embarazos no deseados y, consecuentemente, al aborto. Por otra parte, hay mujeres a quienes les gustaría tener un hijo; pero su compañero las abandona, la patrona amenaza con despedirla de su empleo o el director no acepta muchachas grávidas en su escuela, todo lo cual lleva a la mujer a abortar para sobrevivir y adaptarse a la sociedad en que vive.

En otras palabras, sabemos porque hay tantos abortos inseguros en nuestros países, conocemos las intervenciones que han conseguido reducir los abortos en los países con las menores tasas, pero seguimos

(1) Universidad de Campinas. Brasil afaundes(a) unicamp.br

(2) Centro para la Salud y Política Social. 
manteniendo una discusión simplista sobre el falso dilema de estar a favor o en contra del aborto.

Personas razonables tienen diferentes creencias y opiniones sobre lo que está bien y lo que está mal. En consecuencia, la aceptación de un "pluralismo razonable" parece ser un requisito de las sociedades democráticas. Por otra parte, la gente razonable con concepciones generales muy diferentes puede identificar y ampliar algunas ideas y valores comunes -lo que John Rawls llama "consenso entrecruzado" ["overlapping consensus"]. La construcción del consenso entrecruzado con propósitos sociales no choca con la libertad de los individuos para adherir a sus propias concepciones generales de la moralidad en sus actos personales; y les permite aceptar que, dentro de límites razonables, otras personas puedan actuar de diferente manera y persistir en sus propias ideas de lo que está bien y lo que está mal.

Aplicando este concepto al problema que nos ocupa, nosotros creemos que es eventualmente posible alcanzar un consenso entrecruzado sobre el aborto, teniendo como uno de sus fundamentos el respeto por la diversidad, que supone en todas las personas la capacidad de actuar como plenos agentes morales. Creemos que la mayoría de las personas no está ni totalmente a favor ni absolutamente en contra del aborto en cualquier circunstancia. Al contrario, ya existe un restringido pero significativo consenso entrecruzado con respecto al aborto: 1) a nadie le gusta abortar ni la idea de que otras personas lo hagan, aunque casi todos coinciden en que el aborto está moralmente justificado en ciertas circunstancias; 2) hay demasiados abortos evitables, y 3) el aborto inseguro es un gran problema de salud pública. A fin de definir mejor este consenso y ampliarlo, el debate público debe concentrarse en la forma de prevenir los abortos y en definir cuándo tienen una justificación moral.

Si evitamos los enfrentamientos y la agresividad innecesaria, deberá ser posible ampliar el consenso existente y utilizarlo para legislar y regular el aborto, siempre con una actitud de respeto hacia los diferentes sistemas de valores de cada sociedad. Un diálogo respetuoso permitiría identificar la profundidad y extensión del problema, sus causas y consecuencias, y las intervenciones que han demostrado su eficacia para reducir su impacto. El proceso de búsqueda y expansión del consenso es una tarea de largo plazo y, por eso mismo, urgente, en la cual deben tomar parte los gobiernos, las religiones y la sociedad civil en general. 